\title{
Remote sea-surface temperature variations (2001-2019) in Kuwait Bay: Time series analysis in frequency and time domains
}

\author{
Ali K. Saleh ${ }^{1, *}$, Bader S. Al-Anzi ${ }^{2}$ \\ ${ }^{1}$ College of Graduate Studies, Kuwait University, Kuwait \\ ${ }^{2}$ Dept. of Environmental Technology and Management, College of Life Sciences, Kuwait \\ University, Kuwait \\ *Corresponding author: ali.saleh@grad.ku.edu.kw
}

\begin{abstract}
Because of the direct link between sea temperature and aquatic biodiversity, there is a need to analyze the temporal changes in sea surface temperature in various water bodies, especially the semi-enclosed ones. There has been substantial research undertaken on time series analysis as a powerful technique for studying the characteristics of long-term SST changes at regular time intervals. The present paper aimed to examine the monthly-averaged MODIS SST data (20012019) over Kuwait Bay, i.e., the northwestern corner of the Arabian Gulf. Because different approaches can yield different results, the analysis of the SST time series was conducted using time and frequency domains. The preliminary analysis of the time series reported a significant SST peak in August 2010 that reached nearly $34.2{ }^{\circ} \mathrm{C}\left(\mathrm{SD}=0.17{ }^{\circ} \mathrm{C}\right)$ due to the moderate-intensity El Niño event in 2010. However, in the preceding year, we observed a cool SST anomaly in the range of $-0.5{ }^{\circ} \mathrm{C}$ to $-2.4{ }^{\circ} \mathrm{C}$. The SMK trend test found that monthly climatological SST in September exhibited a significant upward trend $\left(S_{9}=103, \tau=0.6, P=0.0004\right)$. Pettitt's change-point test indicated a significant change in the central tendency of SST data after April 2012. The annual periodicity of the SST in Kuwait Bay was constant over the 19 years. Furthermore, a very weak periodicity of 6-month has been barely noticed. Our present results provide large-scale guidance that affirms the importance of highlighting the severe SST fluctuations in Kuwait's water to understand and improve its marine environmental status.
\end{abstract}

Keywords: Frequency domain; Kuwait Bay; MODIS; SST; time series analysis.

\section{Introduction}

The role of time series analysis (TSA) in studying the long-term variability of various environmental observations has received increased attention across several disciplines, principally in coastal regions where aquatic and biological activities are highly sensitive. TSA detects any change, trend, or development in the environmental data collected by different in situ instruments or satellite sensors. Often, this approach is a crucial aspect of the process of legislation and decision-making on environment-related issues. Hence, TSA accounted for the greatest percentage 
of contribution in the field of environmental sciences (12\%) among other significant fields such as mathematics (10\%), medicine (9\%), and social sciences (9\%) (Maçaira et al., 2018).

One of the most frequently measured and statically analyzed parameters in marine ecosystems is sea surface temperature (SST) due to its importance in aquatic biodiversity (Antão et al., 2020; Descombes et al., 2015; Gentilucci et al., 2020) and water quality (Al-Mutairi et al., 2014, 2015). Consequently, a considerable amount of literature has been published on understanding the dynamics of SST in the spatial or temporal domains (Bulgin et al., 2020; Goela et al., 2016; Hosoda \& Kawamura, 2004; Mak, 1995; Polanco et al., 2011; Silva et al., 2019; Zhang et al., 2016).

The study region, Kuwait Bay (KB), is a semi-enclosed water body located in the northwestern corner of the Arabian Gulf between latitudes $29.32^{\circ} \mathrm{N}$ and $29.58^{\circ} \mathrm{N}$ and longitudes $47.68^{\circ} \mathrm{E}$ and $48.17^{\circ} \mathrm{E}$ (Figure 1). It has a total length of about $45 \mathrm{~km}$ and a maximal width of about $25 \mathrm{~km}$ (AlRashidi et al., 2009), with a total area of approximately $750 \mathrm{~km}^{2}$ (Al-Ghadban, 2004; Al-Mutairi et al., 2014). It is characterized by high surface temperatures (Alosairi et al., 2020) and shallow waters, with an average depth of $5 \mathrm{~m}$ (Al-Zaidan et al., 2006). This region of Kuwait waters is of particular concern due to the existence of several outfalls and effluents along its coastal line, in addition to the slow water flushing time ( $>1$ year) (Rakha et al., 2010) that may affect its water quality.

A large and growing body of literature has investigated the oceanographic characteristics of Kuwait Bay. The study by Al-Abdulghani et al. (2013) offers probably the most comprehensive water quality assessment in this area, considering the impact of different uses and anthropogenic activities. From the spatial distribution of SST, they noted that the highest water temperatures inside the Bay were attributed to the effect of sewage effluents and thermal discharge from power plants. Likewise, Al-Banaa and Rakha (2009) believe that the seasonal peaks of water temperatures, based on in situ CTD data in Sulaibikhat Bay (the southwest corner of Kuwait Bay), are associated with cooling waters from power and desalination plants. Al-Rashidi (2009) analyzed the long-term SST data (1985-2007) from the AVHRR sensor and found that the upward trend in Kuwait Bay is much higher than the global average. Also, he identified the SST peak anomalies in the years 1998 and 2003, which coincided with El Niño events. In another study for statistical validation, Al-Rashidi et al. (2009) compared in situ measurements with coincident AVHRR SSTs and found a near-perfect relation $\left(R^{2}=0.99\right.$, standard error $\left.=0.2{ }^{\circ} \mathrm{C}\right)$. Similarly, Alsahli (2009) used linear regression to model MODIS (MODerate resolution Imaging Spectroradiometer) SST data collected from January 2003 to July 2007 against in situ matchups in Kuwait waters to assess their accuracy and reliability. He showed that the relation between MODIS and in situ data is strong and significant $\left(r^{2}=0.98, n=118\right.$, RMSE $\left.=0.7^{\circ} \mathrm{C}\right)$. Also, he investigated the spatial distribution of SST in Kuwait Bay and showed that the maximum and minimum variability occurred in November $\left(\mathrm{SD}=0.7^{\circ} \mathrm{C}\right)$ and February $\left(\mathrm{SD}=0.4{ }^{\circ} \mathrm{C}\right)$, respectively. 
Given the importance of SST, this study set out to analyze the long-term SST variations in Kuwait Bay to improve our understanding of their frequency and intensity. In this study, the SST time series data were collected at regular intervals from 2001 to 2019. The methodological approach taken in this study is a mixed methodology based on the time domain and the frequency domain. Relying on mid-wave infrared (MWIR) bands, remotely sensed SST images from MODIS were assessed because of their excellent spatiotemporal resolution, with high precision and accuracy (Kilpatrick et al., 2015). Figure 2 is an example of a MODIS-Terra SST image with a spatial resolution of 1-km generated from the standard short-wave (SW) algorithm.

The remainder of this paper is structured into four sections. Section 2 describes the remotely sensed MODIS data used in this study. Section 3 discusses the specific methods of conducting the research and analyses. The results of time-series analyses, including wavelet transform and spectral analysis, are presented in Section 4. The final section draws together a summary of the study and the main conclusions.

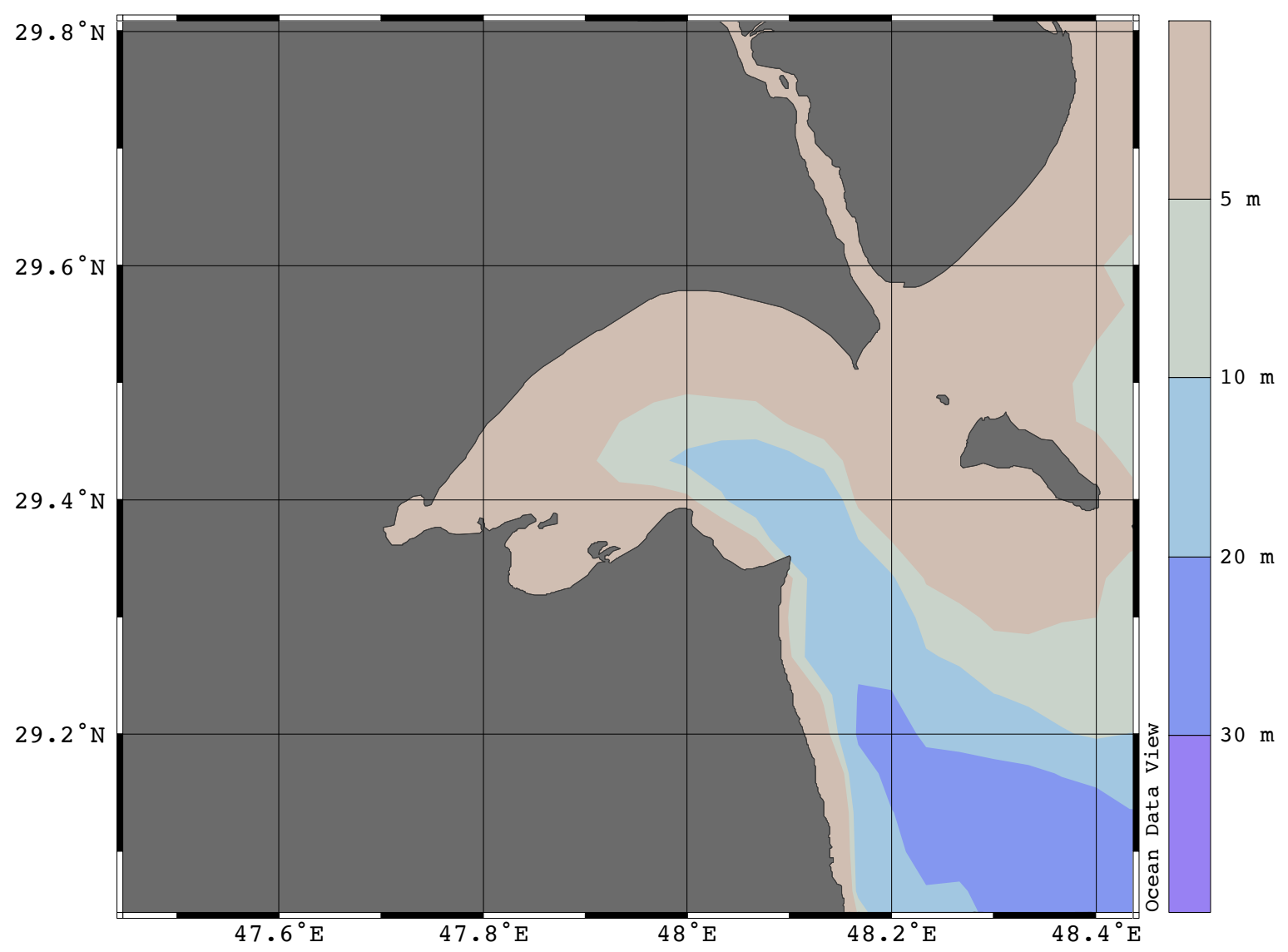

Fig. 1. Bathymetry of Kuwait Bay based on ETOPO 2 min dataset. The color bar on the right represents the water depth. 


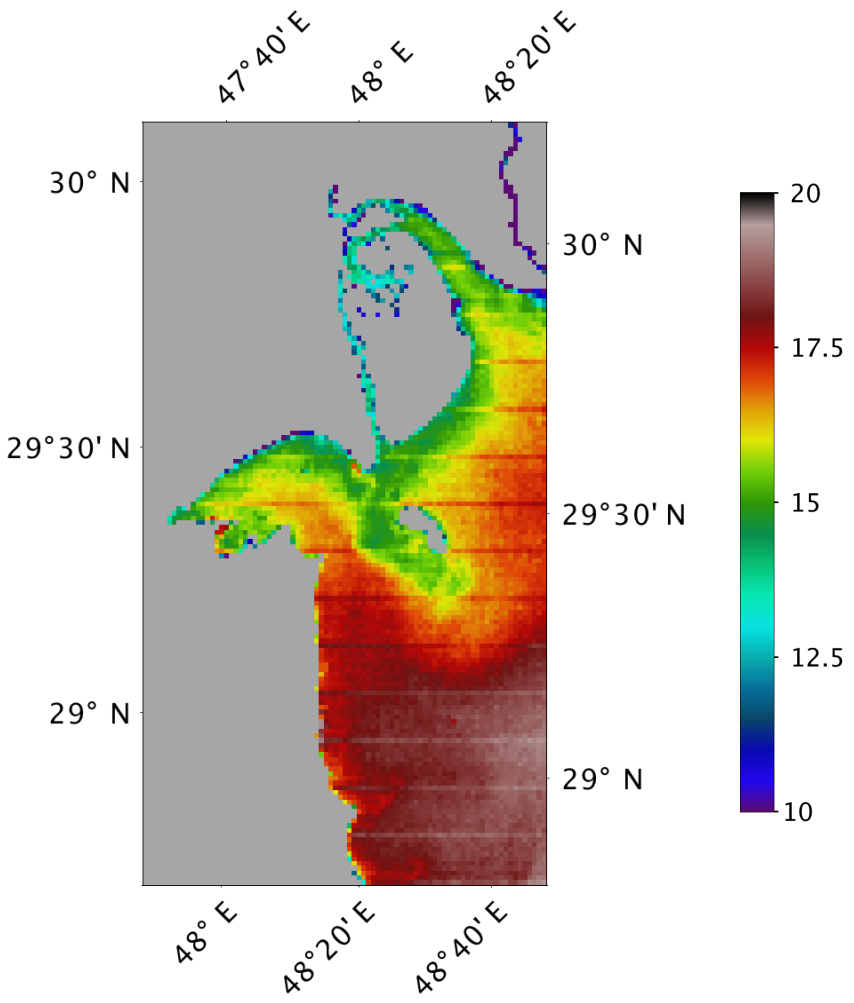

(a)

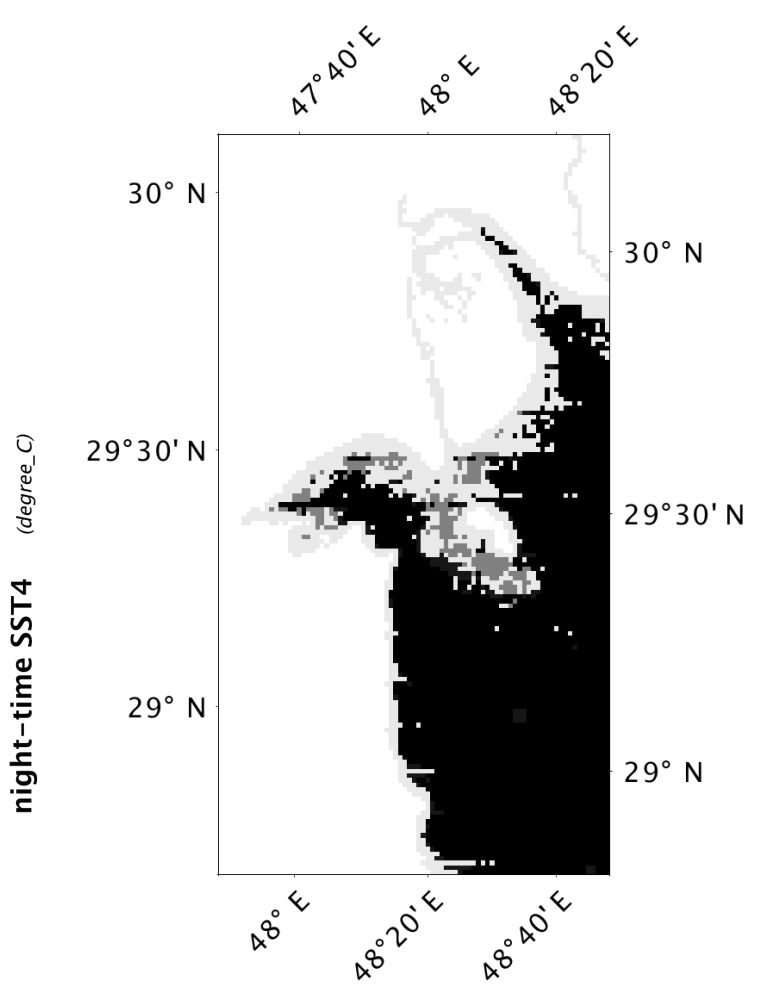

(b)

Fig. 2. (a) Subset scene of Level-2 MODIS SST4 imagery on 10 January 2018 at 7:09 PM and (b) the corresponding quality levels ranging from black (best retrieval) to grey (bad retrieval)

\section{Data source}

MODIS-Terra SST4 data with the latest processing version R2019.0 were acquired from NASA's OceanColor and extracted for Kuwait Bay at a spatial resolution of $4.64 \mathrm{~km}$. The reason behind implementing the short-wave algorithm (MODIS bands 22 and 23) is to get reliable skin SST estimates (Kilpatrick et al., 2015). However, the use of this algorithm is limited to night-time SST retrieval due to the contaminated signal that may occur during the daytime (Brown et al., 1999). A total of 228 Level-3 MODIS images that include the monthly SST observations from January 2001 to December 2019 were analyzed and visualized using SeaDAS software (version 7.5.3). MODIS data processing flow chart from Level-1 to Level-3 is shown in Figure 3a. The quality levels of satellite retrievals ranging from 0 (the best) to 4 (the worst) were visually inspected for validity. For each raster band, the mean value of "valid" pixels ( 54-64 pixels inside the Bay) is calculated by the statistics tool provided by SeaDAS. Figure $3 \mathrm{~b}$ summarizes the general workflow applied in this study. 
(a)

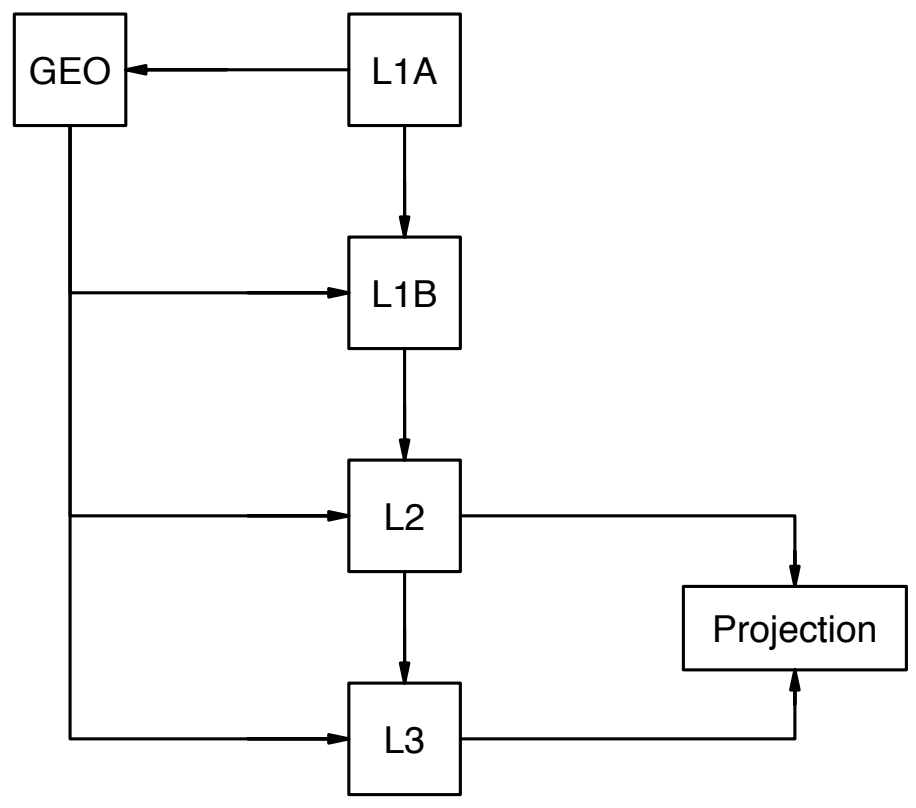

(b)

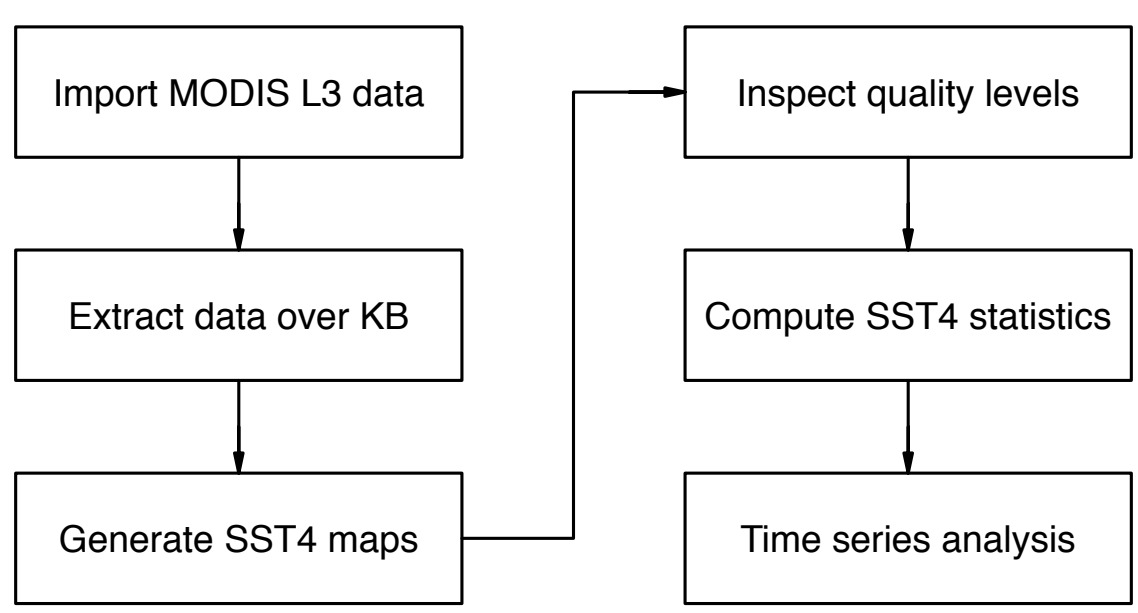

Fig. 3. (a) MODIS data processing flow chart from Level-1 through Level-3. GEO is the geolocation file (Lotliker, 2014). (b) The workflow for analyzing MODIS Level-3 data in this study.

Summary statistics of SST4 data by month can be shown in the aggregated box-whisker plots (Figure 4). For instance, the minimum and maximum sea temperatures were recorded in January $\left(14.7^{\circ} \mathrm{C}\right)$ and August $\left(32.1^{\circ} \mathrm{C}\right)$. From the empirical probability density function (Figure 5), it is apparent that monthly SST between $\sim 29-32^{\circ} \mathrm{C}$ has the highest density among other SST intervals. The secondary peak with lower relative frequency can be seen at SST of $\sim 15-18^{\circ} \mathrm{C}$. 


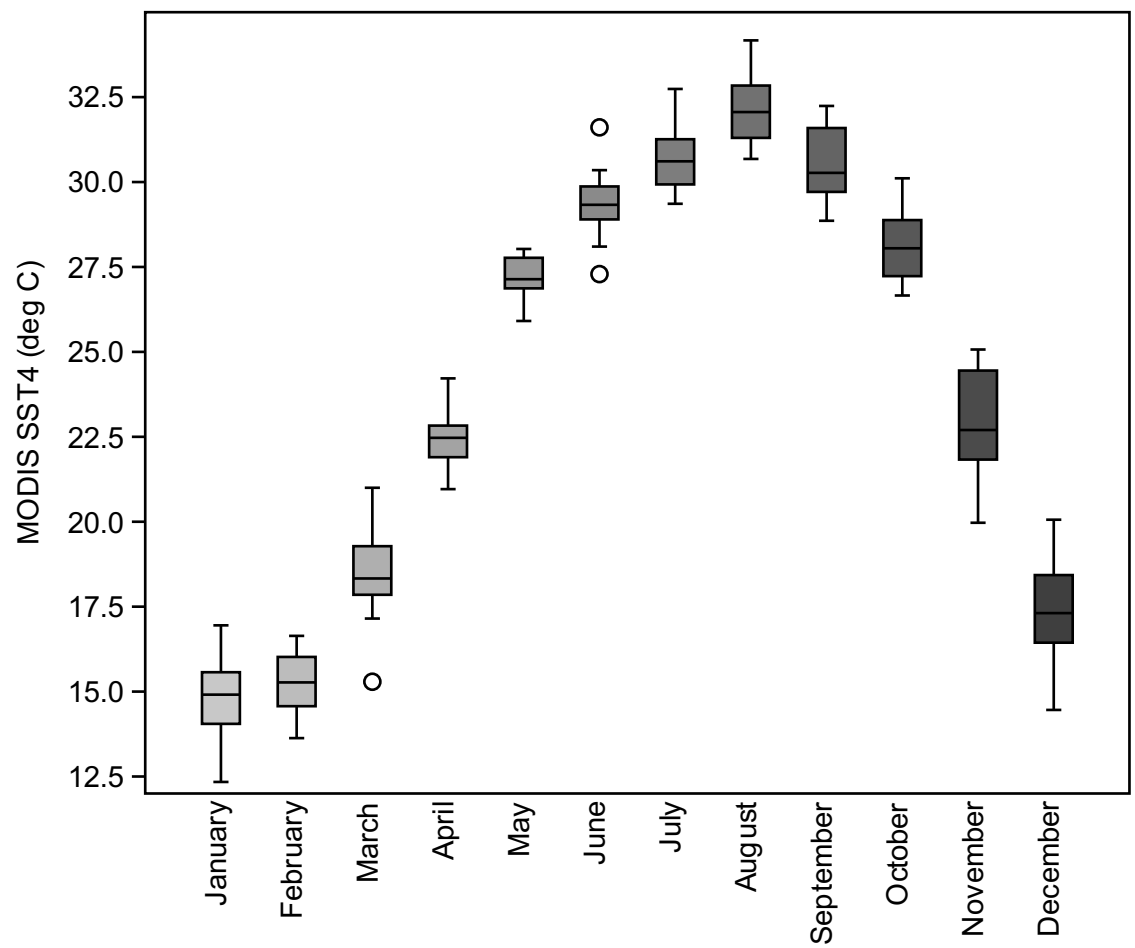

Fig. 4. Box-whisker plots of monthly climatological SST data in Kuwait Bay. For each month, 25-75 percent quartiles are represented by each box. The whiskers are drawn from the top of the box up to the largest data point, less than 1.5 times the box height from the box (the "upper inner fence") and similarly below the box. The black circles represent the extreme outliers.

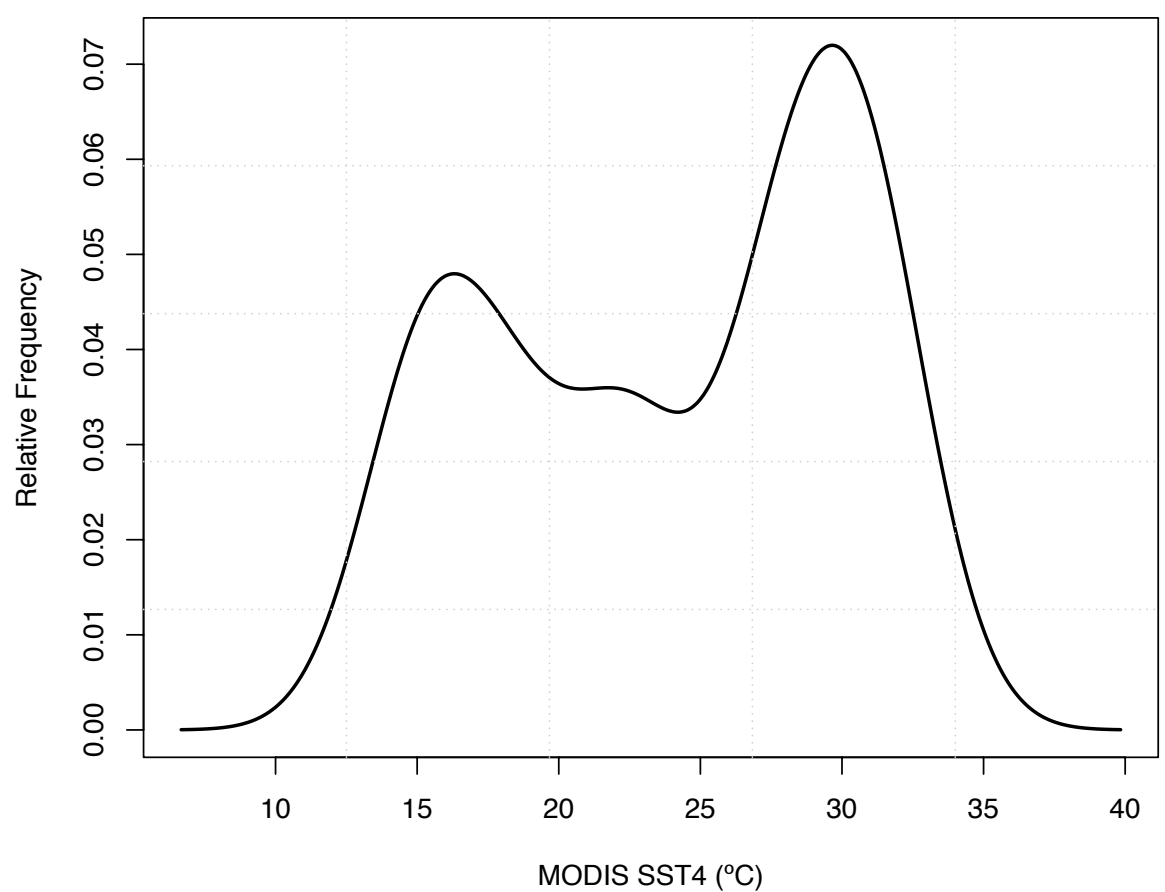

Fig. 5. Empirical probability density function (EPDF) of collected SST data (2001-2019) in Kuwait Bay. 


\section{Methodology}

\subsection{Seasonal-trend decomposition}

Seasonal decomposition of SST time series $\left(Y_{t}\right)$ into seasonal $\left(S_{t}\right)$, trend $\left(T_{t}\right)$, and remainder $\left(R_{t}\right)$ components based on loess (Cleveland et al., 1990) was performed using the native stats package in R software (version 3.6.3). This method is widely available and used in many investigational studies (Cristina et al., 2016; Goela et al., 2016; Rojo et al., 2017). That is, the additive decomposition model used in this study can be defined as

$$
Y_{t}=S_{t}+T_{t}+R_{t}, \quad t=1,2, \ldots, N
$$

\subsection{Trend and change-point tests}

The seasonal Mann-Kendall (SMK) trend test (Hirsch et al., 1982) was implemented to test whether the collected data had a trend considering the conventional seasonal effect. It is a nonparametric test commonly used to detect monotonic trends in environmental and hydrological data sets that aren't normally distributed. Let

$$
Y=\left(Y_{1}, Y_{2}, \ldots, Y_{12}\right)
$$

to be the entire SST series collected over the years consisting of subsets $Y_{1}$ through $Y_{12}$; that is

$$
\begin{gathered}
Y_{1}=\left(y_{11}, y_{12}, \ldots, y_{1 n_{1}}\right) \text { is the subset of January SST data for } n_{1} \text { years, } \\
Y_{2}=\left(y_{21}, y_{22}, \ldots, y_{2 n_{2}}\right) \text { is the subset of February SST data for } n_{2} \text { years, etc. }
\end{gathered}
$$

where $y_{i j}$ denotes the datum obtained for the season in year $j$. Here, we assume the season is a month. The overall seasonal Kendall test statistic $\left(S_{k}\right)$ is the sum of individual Kendall's $S_{i}$ statistics for each of the $i=1$ to $g$ seasons.

$$
\begin{aligned}
& S_{k}=\sum_{i=1}^{g} S_{i}, \\
& S_{i}=\sum_{k=1}^{n_{i}-1} \sum_{j=k+1}^{n_{i}} \operatorname{sign}\left(y_{i j}-y_{i k}\right),
\end{aligned}
$$

were

$$
\operatorname{sign}\left(y_{i j}-y_{i k}\right)= \begin{cases}+1 & y_{i j}-y_{i k}>0, \\ 0 & y_{i j}-y_{i k}=0, \\ -1 & y_{i j}-y_{i k}<0 .\end{cases}
$$

The nonparametric correlation coefficient of the SMK test is calculated according to:

$$
\tau=\frac{S_{k}}{n(n-1) / 2}
$$


For any data set, it is possible to detect the shift in its central tendency based on Pettitt's nonparametric test (Pettitt, 1979). The SST time series was tested for a single value change using the trend package (Pohlert, 2020) in R software according to:

$$
U_{t, T}=\sum_{i=1}^{t} \sum_{j=t+1}^{T} \operatorname{sign}\left(y_{i}-y_{j}\right)
$$

where $U_{t, T}$ represents the Mann-Whitney statistic. The statistical change point (SCP) test statistic is the maximum of the absolute value of the vector:

$$
K_{T}=\max \left|U_{t, T}\right| \text {. }
$$

The probable change-point is located in the series at $K_{T}$. The approximate probability for a twosided test is considered good for $p \leq 0.5$ and is estimated according to:

$$
p \cong 2 e^{-6 K_{T}^{2} /\left(T^{3}+T^{2}\right)} \text {. }
$$

\subsection{Wavelet transform and spectral analysis}

The univariate SST time series for Kuwait Bay was subjected to frequency analysis using continuous wavelet transform (CWT) and Fourier spectrum to understand its periodic behavior across time (Rösch \& Schmidbauery, 2018). Morlet wavelet function, among other CWT functions such as derivative of Gaussian (DOG) and Paul wavelet functions, is the most frequently used because of its performance (Addison, 2017). The Morlet wavelet is expressed as (Torrence \& Compo, 1998):

$$
\psi_{0}(\eta)=\pi^{-1 / 4} e^{i \omega_{0} \eta} e^{-\eta^{2} / 2},
$$

where $\eta$ is the time parameter, and $\omega_{0}$ is the frequency of the mother wavelet. The analysis was based on the practical guide developed by Torrence and Compo (1998). The analysis results were visualized as a period image of the wavelet power spectrum.

Evolutionary power spectral analysis was carried out using the Lomb-Scargle method (Lomb, 1976; Scargle, 1982). Briefly, the Lomb-Scargle normalized periodogram can be expressed as (Press \& Rybicki, 1989):

$$
P_{N}(\omega)=\frac{1}{2 \sigma^{2}}\left\{\frac{\left[\sum_{j}\left(y_{j}-\bar{y}\right) \cos \omega\left(t_{j}-\tau\right)\right]^{2}}{\sum_{j} \cos ^{2} \omega\left(t_{j}-\tau\right)}+\frac{\left[\sum_{j}\left(y_{j}-\bar{y}\right) \sin \omega\left(t_{j}-\tau\right)\right]^{2}}{\sum_{j} \sin ^{2} \omega\left(t_{j}-\tau\right)}\right\},
$$

where $\omega$ is the angular frequency, and $\sigma^{2}$ is the data's variance. The time offset $\tau$ is calculated via

$$
\tan (2 \omega \tau)=\frac{\sum_{j} \sin 2 \omega t_{j}}{\sum_{j} \cos 2 \omega t_{j}}
$$

A sliding window of 24 months was chosen since the longest SST cycle was $\sim 12$ months (i.e., 1.5-2 times the annual cycle is acceptable). The maximum frequency was set to 0.5 (cycles/unit) to highlight the low-frequency power. However, from our trials, enlarging the frequency had a negligible effect on the results. It should be noted that the standard Lomb-Scargle periodogram can be affected by measurement errors and the mean subtraction (Zechmeister \& Kürster, 2009), and hence, caution must be applied. To overcome these shortages, other techniques are proposed by Zechmeister and Kürster (2009). However, their usage is beyond the scope of this paper. All 
spectral and wavelet analyses were performed using the Acycle package (version 2.2) (Li et al., 2019) developed in MATLABC.

\section{Results and discussion}

\subsection{Time-domain analysis of SST}

Figure 6 shows the original time series (top panel) and the three decomposed components: (i) the seasonality (also called cyclical effect) (second panel), (ii) the trend (third panel), and (iii) the remainder (bottom panel) of sea surface temperatures for Kuwait Bay over a time frame from January 2001 to December 2019. From the original time series, there was a significant SST peak in August 2010 that reached $34.2^{\circ} \mathrm{C}$ (standard deviation $=0.17^{\circ} \mathrm{C}$ ) as compared to that in August $2009\left(\mathrm{SST}=30.7^{\circ} \mathrm{C}\right.$, standard deviation $\left.=0.52{ }^{\circ} \mathrm{C}\right)$ and August $2011\left(\mathrm{SST}=32.1^{\circ} \mathrm{C}\right.$, standard deviation $\left.=0.49^{\circ} \mathrm{C}\right)$. In Figure 7, the SST pattern shows the cool anomaly $\left(-0.5^{\circ} \mathrm{C}\right.$ to $\left.-2.4{ }^{\circ} \mathrm{C}\right)$ in August 2009 and the warm anomaly $\left(1.2{ }^{\circ} \mathrm{C}\right.$ to $\left.2.8^{\circ} \mathrm{C}\right)$ in August 2010. It should be noted that the base period for calculating the anomalies has been extended by two years (i.e., 2000-2020) to improve the estimation accuracy. The warm SST anomaly is probably due to the influence of a moderate intensity El Niño event in 2010. The year and duration of the El Niño event were from WMO (2014). The seasonal effects are clear and strong in the second panel (Figure 6). In the third panel, there are random fluctuations but no general upward or downward trend away from a horizontal line. However, there appears to be a sharp increase in the trendline from $23.5^{\circ} \mathrm{C}$ in May 2009 to $25^{\circ} \mathrm{C}$ in June 2010 , followed by a sharp decrease to $23{ }^{\circ} \mathrm{C}$ in January 2012 . The fourth panel shows the remainder component (or the residuals) that is not explained by the trend and the seasonal components.

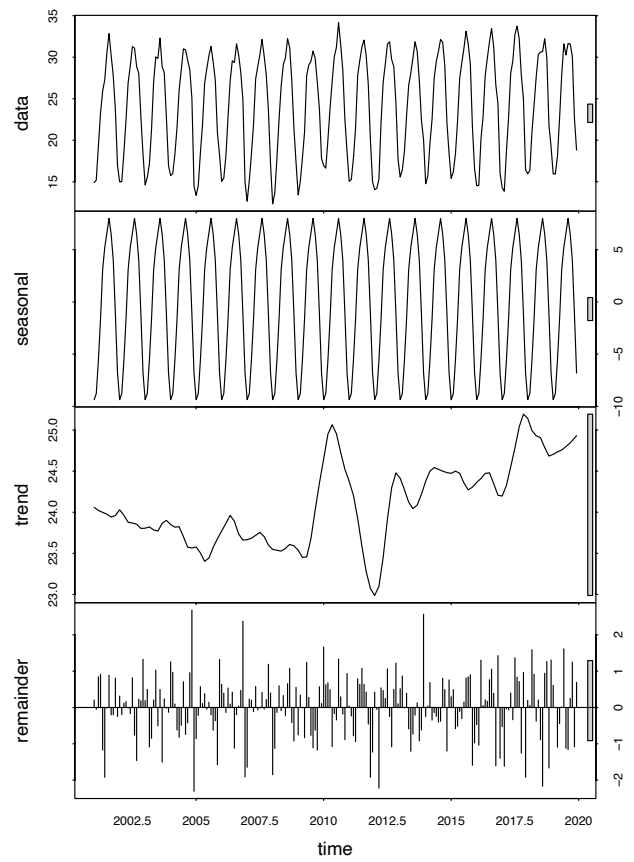

Fig. 6. Decomposition plot of monthly average SST (2001-2019) over Kuwait Bay in degrees Celsius. The grey bars on the right are magnitude guides - each bar represents the same magnitude. 


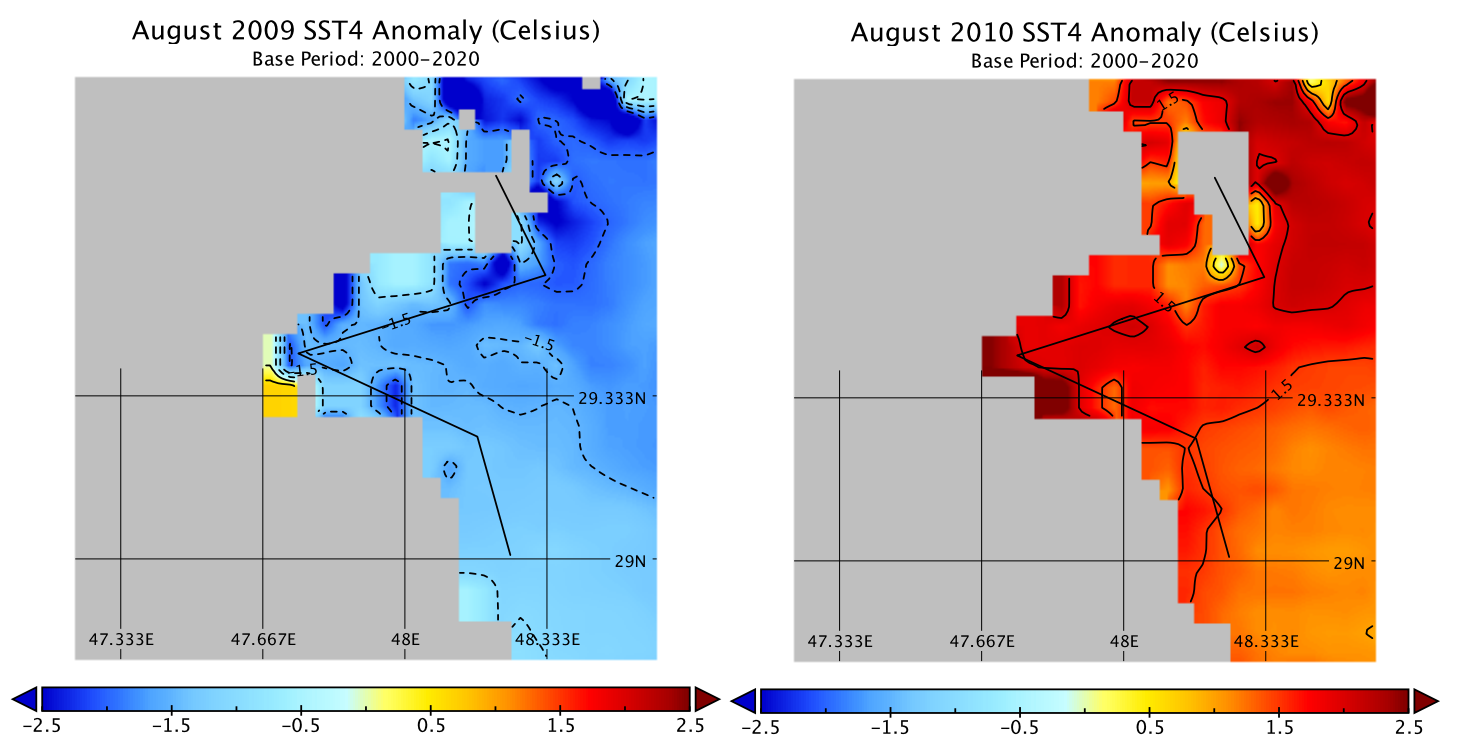

(a)

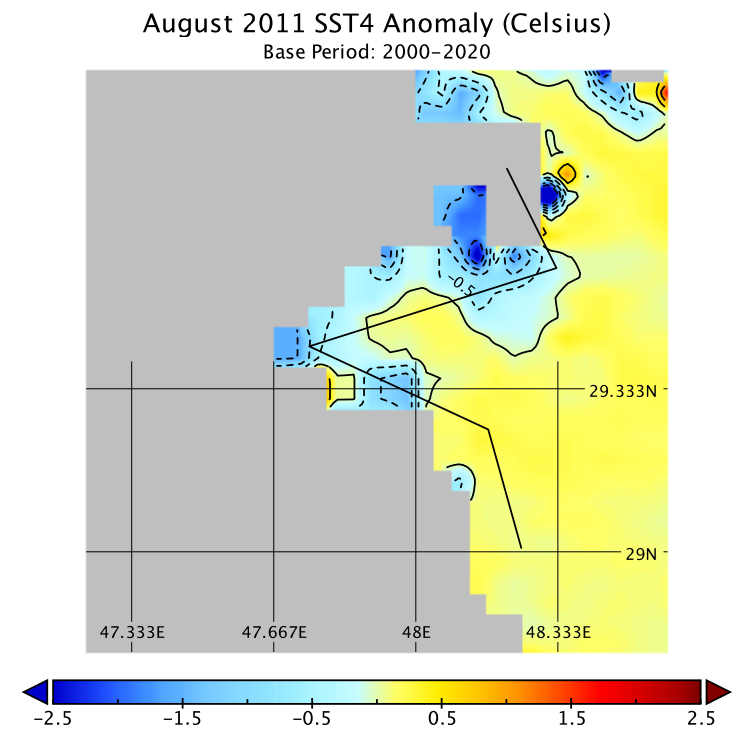

(b)

Fig. 7. MODIS-derived sea surface temperature data for Kuwait Bay showing the anomalies of August 2009 and August 2010 (a) in comparison to SST anomalies of August 2011 (b). The anomalies are interpolated and calculated as the difference between monthly and long-term monthly climatology data collected during the base period. The contour lines are shown for every major and minor scale tick. The grey color represents the land mask.

To explore the seasonal decomposition, the cycle-subseries of each month (e.g., all SST values in January from 2001 to 2019) is displayed in Figure 8. According to the seasonal Mann-Kendall trend test, it was noticed that SST had an upward and significant (i.e., $P<0.05$ ) trend in September $\left(S_{9}=103, \tau=0.6, P=0.0004\right)$ and to a lesser extent in May $\left(S_{5}=91, \tau=0.53, P=0.002\right)$ and June $\left(S_{6}=79, \tau=0.46, P=0.006\right)$. Thus, the global trend for the entire SST series is at $S=504$ $(P=3.774 \mathrm{E}-07)$ with a seasonal Sen's slope for linear rate of change of 0.07 . 
There was a significant probability approximate $(p$-value $=0.4987)$ in the central tendency of the SST time series at $K=136$ with a $\widehat{P}$ of 1660 . This probable-change point corresponds to SST collected in April 2012 (Figure 9). The underlying reasons for this finding are unclear at present.

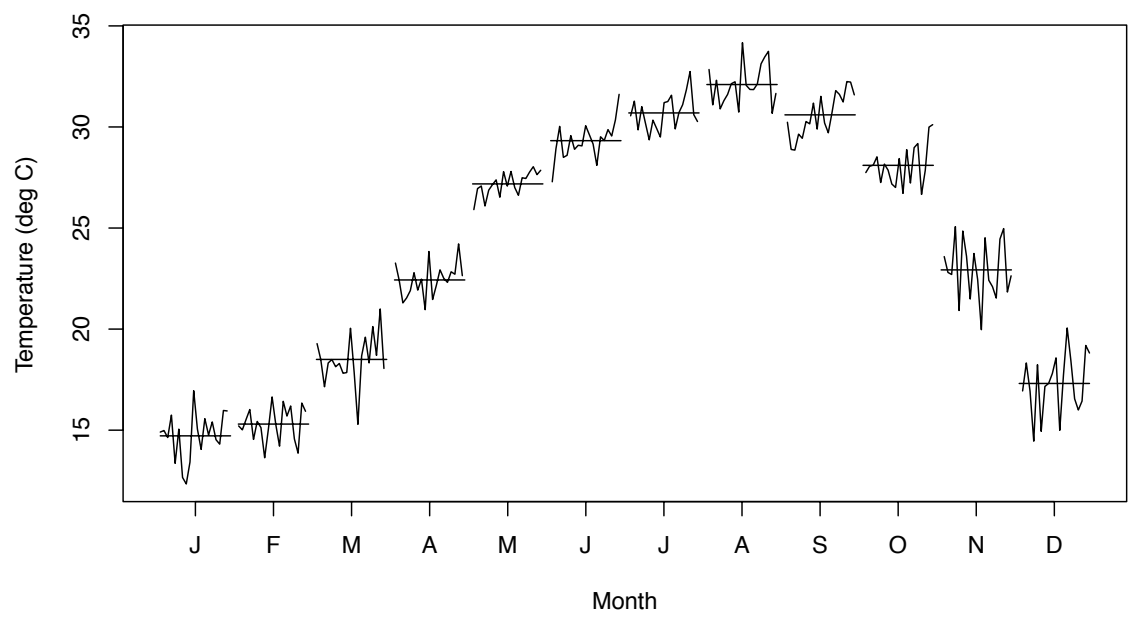

Fig. 8. Extracted monthly subseries from the SST time series (2001-2019). The horizontal line represents the monthly climatological sea surface temperature.

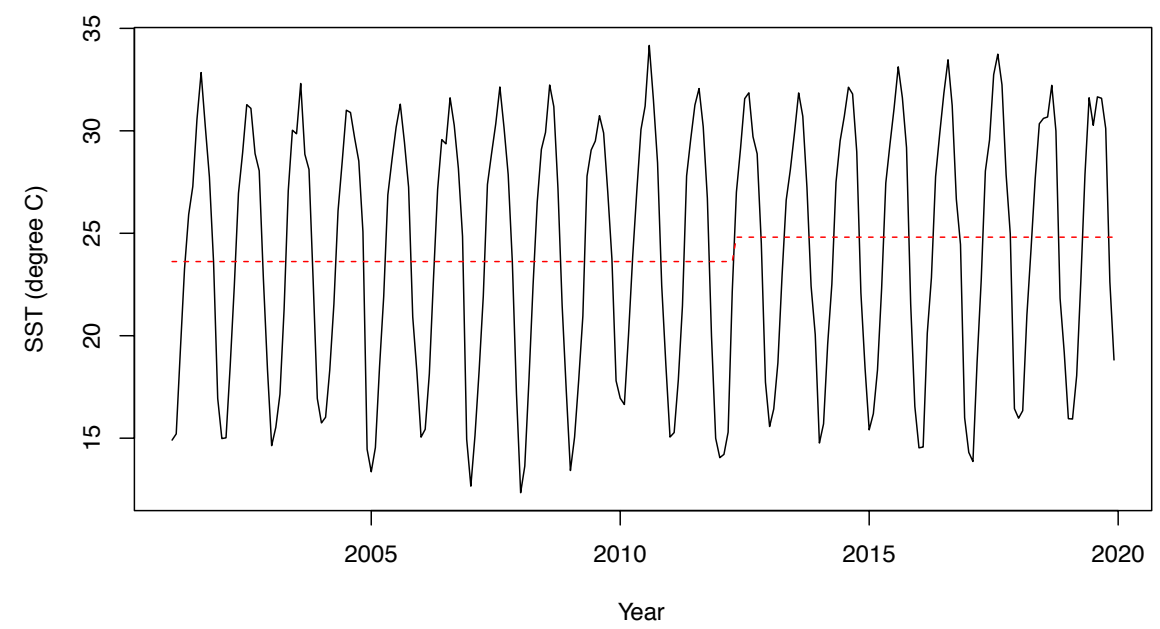

Fig. 9. Time series plot of SST. The dashed red line represents the central tendency of SST before and after the change point in the series (i.e., April 2012).

\subsection{Frequency-domain analysis of SST}

The Morlet wavelet spectrum for the SST series obtained by the MODIS sensor is calculated and is displayed in Figure 10. Overall, the records show that a dark red shade is assigned to the largest value of the wavelet coefficient and illustrates a constant period of 1 year (Figure 10a). The area below the cone of influence (black line) is highly affected by the edge effects at the beginning and the end of the analysis and should be ignored. The corresponding global wavelet spectrum in Figure $10 \mathrm{~b}$ clearly shows the aforementioned strong periodicity of 1 year. Since the annual period has the strongest component and hence, the highest total energy of the signal, other weak 
periodicities cannot be detected easily (Andreo et al., 2006). However, a detailed analysis of the Lomb-Scargle results (Figure 11) allowed us to observe the less obvious 6-monthly periodicity of SST (frequency $=0.167$ cycles/unit), together with the evident peak corresponding to the annual periodicity (frequency $=0.083$ cycles/unit). These results mirror those of the previous studies that have applied frequency analysis to rainfall (Andreo et al., 2006) and sea level (Sudha Rani et al., 2017) data.

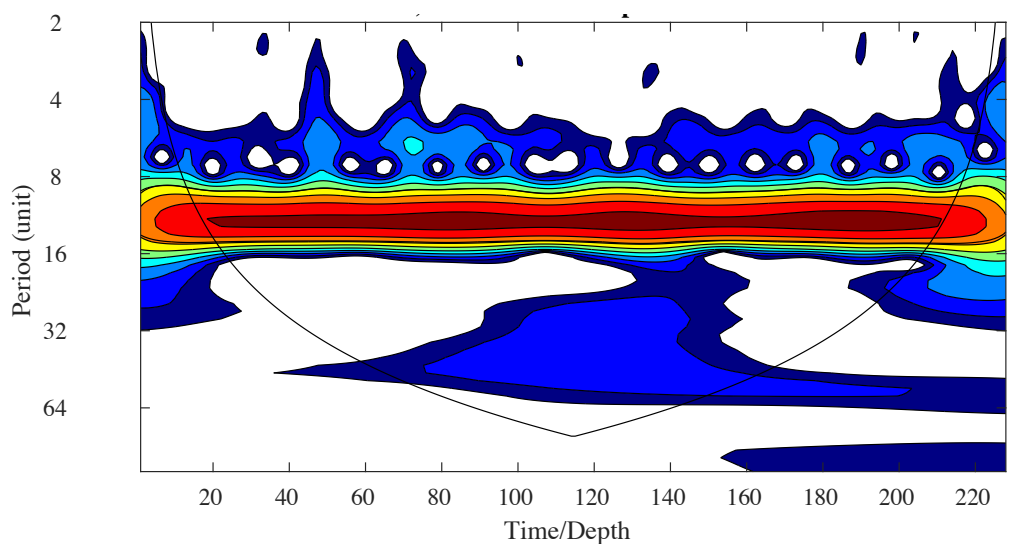

(a)

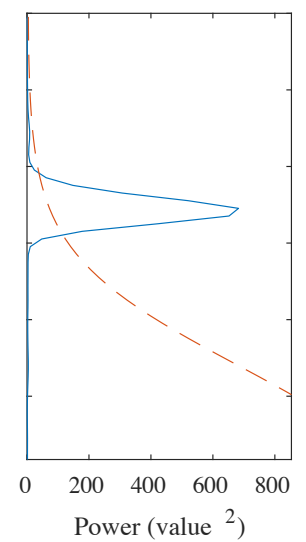

(b)

Fig. 10. Morlet wavelet analysis of monthly average SST (2001-2019) over Kuwait Bay: (a) continuous wavelet transform (CWT) power spectra of the series. The left axis is the period (in months). The bottom axis is time (months). (b) The global wavelet spectrum.

(a)

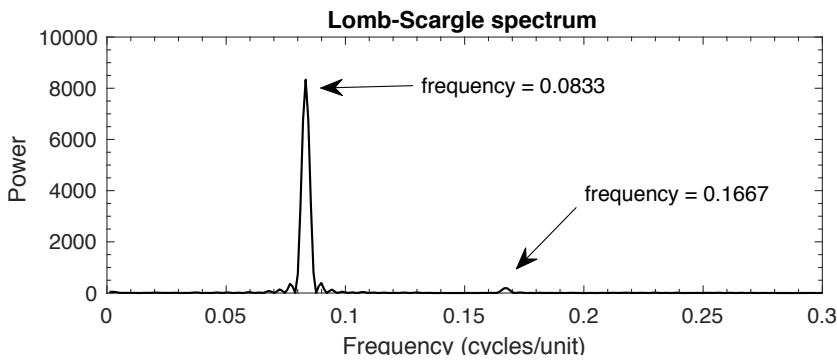

(b)
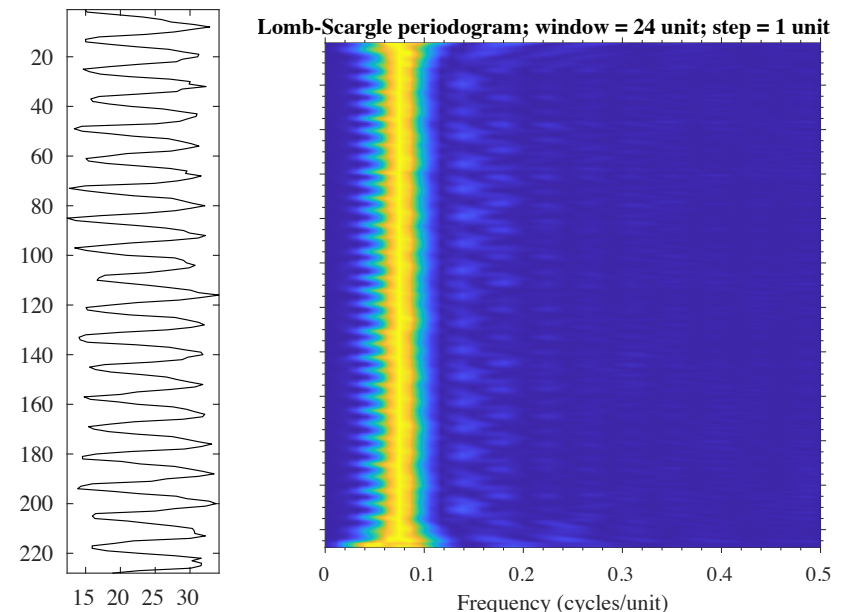

Fig. 11. Lomb-Scargle spectrum (a) and normalized periodogram with a unit step (b) of monthly average SST (2001-2019) over Kuwait Bay. The left axes in (b) represent the time (months). 


\section{Conclusions}

This study has examined the SST variations for 19 years within Kuwait Bay, an important area of Kuwait waters. The seasonal decomposition of the data set revealed that the seasonality is clear and strong, whereas the irregular components were generally not consistent. The findings indicate that the SST subseries had an upward trend in September (2001-2019), while other months have exhibited a reasonable SST fluctuation. However, the SMK test revealed that the global trend for the entire SST series is at $S=504$, with a seasonal Sen's slope for a linear rate of change of 0.07. We observed that the central tendency of the monthly SST in recent years, from 2012 to 2019, was higher than that of the years 2001-2011. In the frequency domain, the apparent strong period associated with the highest frequency is the stationary 12-month. However, a less noticeable periodicity of 6-month can be detected with the Lomb-Scargle periodogram. Relying on MODIS data, the analysis of the long-term SST changes undertaken here has extended our knowledge of extreme SST events in one of the warmest ecosystems. These findings make several contributions to the current literature.

In terms of directions for future research, further work could examine the mechanisms of SST anomalies in Kuwait Bay since several questions remain to be answered.

\section{References}

Addison, P. S. (2017). The Illustrated Wavelet Transform Handbook: Introductory Theory and Applications in Science, Engineering, Medicine and Finance. CRC Press.

Al-Abdulghani, E., El-Sammak, A., \& Sarawi, M. (2013). Environmental assessment of Kuwait Bay: an integrated approach. Journal of Coastal Conservation, 17(3), 445-462. https://doi.org/10.1007/s11852-013-0242-7

Al-Banaa, K., \& Rakha, K. (2009). Seasonal Variability of Temperature Measurements in a Shallow Bay. Journal of Coastal Research, 782-786. http://www.jstor.org/stable/25737685

Al-Ghadban, A. (2004). Assessment of suspended sediment in Kuwait bay using Landsat and spot images. Kuwait Journal of Science \& Engineering, 31(2), 155-172.

Al-Mutairi, N., Abahussain, A., \& El-Battay, A. (2014). Spatial and temporal characterizations of water quality in Kuwait Bay. Marine Pollution Bulletin, 83(1), 127-131. https://doi.org/10.1016/j.marpolbul.2014.04.009

Al-Mutairi, N., AbaHussain, A., \& El-Battay, A. (2015). Spatial assessment of monitoring network in coastal waters: a case study of Kuwait Bay. Environmental Monitoring and Assessment, 187(10), 621. https://doi.org/10.1007/s10661-015-4841-7 
Al-Rashidi, T. B. (2009). An analysis of drivers of seawater temperature in Kuwait Bay, Arabian Gulf. University of Southampton.

Al-Rashidi, T. B., El-Gamily, H. I., Amos, C. L., \& Rakha, K. A. (2009). Sea surface temperature trends in Kuwait Bay, Arabian Gulf. Natural Hazards, 50(1), 73-82. https://doi.org/10.1007/s11069-008-9320-9

Al-Zaidan, A., Kennedy, H., Jones, D., \& Al-Mohanna, S. (2006). Role of microbial mats in Sulaibikhat Bay (Kuwait) mudflat food webs: evidence from $\delta 13 \mathrm{C}$ analysis. Marine Ecology Progress Series, 308, 27-36. https://doi.org/10.3354/meps308027

Alosairi, Y., Alsulaiman, N., Rashed, A., \& Al-Houti, D. (2020). World record extreme sea surface temperatures in the northwestern Arabian/Persian Gulf verified by in situ measurements. Marine Pollution Bulletin, 161, Article 111766. https://doi.org/10.1016/j.marpolbul.2020.111766

Alsahli, M. (2009). Characterizing Surface Temperature and Clarity of Kuwait's Seawaters Using Remotely Sensed Measurements and GIS Analyses [University of Kansas]. https://kuscholarworks.ku.edu/handle/1808/5969

Andreo, B., Jiménez, P., Durán, J. J., Carrasco, F., Vadillo, I., \& Mangin, A. (2006). Climatic and hydrological variations during the last 117-166 years in the south of the Iberian Peninsula, from spectral and correlation analyses and continuous wavelet analyses. Journal of Hydrology, 324(1-4), 24-39. https://doi.org/10.1016/j.jhydrol.2005.09.010

Antão, L. H., Bates, A. E., Blowes, S. A., Waldock, C., Supp, S. R., Magurran, A. E., Dornelas, M., \& Schipper, A. M. (2020). Temperature-related biodiversity change across temperate marine and terrestrial systems. Nature Ecology \& Evolution, 4(7), 927-933. https://doi.org/10.1038/s41559-020-1185-7

Brown, O. B., Minnett, P. J., Evans, R., Kearns, E., Kilpatrick, K., Kumar, A., Sikorski, R., \& Závody, A. (1999). MODIS Infrared Sea Surface Temperature Algorithm Theoretical Basis Document, Version 2.0. University of Miami. https://modis.gsfc.nasa.gov/data/atbd/atbd_mod25.pdf

Bulgin, C. E., Merchant, C. J., \& Ferreira, D. (2020). Tendencies, variability and persistence of sea surface temperature anomalies. Scientific Reports, 10(1), Article 7986. https://doi.org/10.1038/s41598-020-64785-9

Cleveland, R. B., Cleveland, W. S., McRae, J. E., \& Terpenning, I. (1990). STL: A SeasonalTrend Decomposition Procedure Based on Loess. Journal of Official Statistics, 6(1), 3-33. 
Cristina, S., Cordeiro, C., Lavender, S., Costa Goela, P., Icely, J., \& Newton, A. (2016). MERIS Phytoplankton Time Series Products from the SW Iberian Peninsula (Sagres) Using Seasonal-Trend Decomposition Based on Loess. Remote Sensing, 8(6), Article 449. https://doi.org/10.3390/rs8060449

Descombes, P., Wisz, M. S., Leprieur, F., Parravicini, V., Heine, C., Olsen, S. M., Swingedouw, D., Kulbicki, M., Mouillot, D., \& Pellissier, L. (2015). Forecasted coral reef decline in marine biodiversity hotspots under climate change. Global Change Biology, 21(7), 2479-2487. https://doi.org/10.1111/gcb.12868

Gentilucci, M., Parisi, C., Coppola, M. R., Majdoubi, F.-Z., Madonna, A., \& Guerriero, G. (2020). Influence of Mediterranean Sea Temperature Increase on Gaeta Gulf (Tyrrhenian Sea) Biodiversity. Proceedings of the Zoological Society. https://doi.org/10.1007/s12595-020-00334-6

Goela, P. C., Cordeiro, C., Danchenko, S., Icely, J., Cristina, S., \& Newton, A. (2016). Time series analysis of data for sea surface temperature and upwelling components from the southwest coast of Portugal. Journal of Marine Systems, 163, 12-22. https://doi.org/10.1016/j.jmarsys.2016.06.002

Hirsch, R. M., Slack, J. R., \& Smith, R. A. (1982). Techniques of trend analysis for monthly water quality data. Water Resources Research, 18(1), 107-121. https://doi.org/10.1029/WR018i001p00107

Hosoda, K., \& Kawamura, H. (2004). Examination of the Merged Sea Surface Temperature Using Wavelet Analysis. Journal of Oceanography, 60(5), 843-852. https://doi.org/10.1007/s10872-004-5777-7

Kilpatrick, K. A., Podestá, G., Walsh, S., Williams, E., Halliwell, V., Szczodrak, M., Brown, O. B., Minnett, P. J., \& Evans, R. (2015). A decade of sea surface temperature from MODIS. Remote Sensing of Environment, 165, 27-41. https://doi.org/10.1016/j.rse.2015.04.023

Li, M., Hinnov, L., \& Kump, L. (2019). Acycle: Time-series analysis software for paleoclimate research and education. Computers \& Geosciences, 127, 12-22. https://doi.org/10.1016/j.cageo.2019.02.011

Lomb, N. R. (1976). Least-squares frequency analysis of unequally spaced data. Astrophysics and Space Science, 39(2), 447-462. https://doi.org/10.1007/BF00648343

Lotliker, A. (2014). Practical manual for processing MODIS-Aqua satellite ocean colour data using SeaDAS (v6.4). 
Maçaira, P. M., Tavares Thomé, A. M., Cyrino Oliveira, F. L., \& Carvalho Ferrer, A. L. (2018). Time series analysis with explanatory variables: A systematic literature review. Environmental Modelling \& Software, 107, 199-209. https://doi.org/10.1016/j.envsoft.2018.06.004

Mak, M. (1995). Orthogonal Wavelet Analysis: Interannual Variability in the Sea Surface Temperature. Bulletin of the American Meteorological Society, 76(11), 2179-2186. https://doi.org/10.1175/1520-0477(1995)076<2179:OWAIVI>2.0.CO;2

Pettitt, A. N. (1979). A Non-Parametric Approach to the Change-Point Problem. Journal of the Royal Statistical Society. Series C (Applied Statistics), 28(2), 126-135. https://doi.org/10.2307/2346729

Pohlert, T. (2020). trend: Non-Parametric Trend Tests and Change-Point Detection (1.1.4). https://cran.r-project.org/package=trend

Polanco, J., Ganzedo, U., Sáenz, J., Caballero-Alfonso, A. M., \& Castro-Hernández, J. J. (2011). Wavelet analysis of correlation among Canary Islands octopus captures per unit effort, sea-surface temperatures and the North Atlantic Oscillation. Fisheries Research, 107(1), 177-183. https://doi.org/10.1016/j.fishres.2010.10.019

Press, W. H., \& Rybicki, G. B. (1989). Fast algorithm for spectral analysis of unevenly sampled data. The Astrophysical Journal, 338, 277-280. https://doi.org/10.1086/167197

Rakha, K. A., Al-Banaa, K., \& Al-Hulail, F. (2010). Flushing Characteristics of Kuwait Bay. Kuwait Journal of Science \& Engineering, 37(1A), 111-125.

Rojo, J., Rivero, R., Romero-Morte, J., Fernández-González, F., \& Pérez-Badia, R. (2017). Modeling pollen time series using seasonal-trend decomposition procedure based on LOESS smoothing. International Journal of Biometeorology, 61(2), 335-348. https://doi.org/10.1007/s00484-016-1215-y

Rösch, A., \& Schmidbauery, H. (2018). WaveletComp 1.1: A guided tour through the R package.

Scargle, J. D. (1982). Studies in Astronomical Time Series Analysis. II. Statistical Aspects of Spectral Analysis of Unevenly Spaced Data. The Astrophysical Journal, 263, 835-853. https://doi.org/10.1086/160554 
Silva, C. B., Silva, M. E. S., Krusche, N., Ambrizzi, T., de Jesus Ferreira, N., \& da Silva Dias, P. L. (2019). The analysis of global surface temperature wavelets from 1884 to 2014. Theoretical and Applied Climatology, 136(3), 1435-1451. https://doi.org/10.1007/s00704-018-2569-3

Sudha Rani, N. N. V, Satyanarayana, A. N. V, \& Bhaskaran, P. K. (2017). Assessment of Climatological Trends of Sea Level over the Indian Coast Using Artificial Neural Network and Wavelet Techniques. Pure and Applied Geophysics, 174(4), 1527-1546. https://doi.org/10.1007/s00024-017-1501-6

Torrence, C., \& Compo, G. P. (1998). A Practical Guide to Wavelet Analysis. Bulletin of the American Meteorological Society, 79(1), 61-78. https://doi.org/10.1175/15200477(1998)079<0061:APGTWA>2.0.CO;2

WMO. (2014). El Niño/ Southern Oscillation, WMO-No. 1145. World Meteorological Organization. https://library.wmo.int/doc_num.php?explnum_id=7888

Zechmeister, M., \& Kürster, M. (2009). The generalised Lomb-Scargle periodogram. Astronomy \& Astrophysics, 496(2), 577-584. https://doi.org/10.1051/0004-6361:200811296

Zhang, Y., Cabilio, P., \& Nadeem, K. (2016). Improved Seasonal Mann-Kendall Tests for Trend Analysis in Water Resources Time Series. In W. K. Li, D. A. Stanford, \& H. Yu (Eds.), Advances in Time Series Methods and Applications: The A. Ian McLeod Festschrift (pp. 215-229). Springer New York. https://doi.org/10.1007/978-1-4939-6568-7_10

Submitted: $\quad 08 / 03 / 2021$

Revised: $\quad 05 / 07 / 2021$

Accepted: $\quad$ 12/08/2021

DOI: $\quad 10.48129 / \mathrm{kjs} .12873$ 